\title{
A NEW GENERATION CHEMICAL FLOODING SIMULATOR
}

\author{
Semi-annual Report for the Period \\ October 1, 2003 - March 30, 2004 \\ by \\ Gary A. Pope, Kamy Sepehrnoori, and Mojdeh Delshad \\ May 2004
}

Work Performed under Contract No. DE-FC-26-00BC15314

\author{
Sue Mehlhoff, Project Manager \\ U.S. Dept of Energy \\ National Petroleum Technology Office \\ One West Third Street, Suite 1400 \\ Tulsa, OK 74103-3159
}

Prepared by

Center for Petroleum and Geosystems Engineering

The University of Texas at Austin

Austin, TX 78712 


\section{DISCLAIMER}

This report was prepared as an account of work sponsored by an agency of the United States Government. Neither the United States Government nor any agency thereof, nor any of their employees, makes any warranty, express or implied, or assumes any legal liability or responsibility for the accuracy, completeness, or usefulness of any information, apparatus, product, or process disclosed, or represents that its use would not infringe privately owned rights. Reference herein to any specific commercial product, process, or service by trade name, trademark, manufacturer, or otherwise does not necessarily constitute or imply its endorsement, recommendation, or favoring by the United States Government or any agency thereof. The views and opinions of authors expressed herein do not necessarily state or reflect those of the United States Government or any agency thereof. 


\begin{abstract}
The premise of this research is that a general-purpose reservoir simulator for several improved oil recovery processes can and should be developed so that highresolution simulations of a variety of very large and difficult problems can be achieved using state-of-the-art algorithms and computers. Such a simulator is not currently available to the industry. The goal of this proposed research is to develop a newgeneration chemical flooding simulator that is capable of efficiently and accurately simulating oil reservoirs with at least a million gridblocks in less than one day on massively parallel computers. Task 1 is the formulation and development of solution scheme, Task 2 is the implementation of the chemical module, and Task 3 is validation and application. We have made significant progress on all three tasks and we are on schedule on both technical and budget. In this report, we will detail our progress on Tasks 1 through 3 for the first half of the third year of the project.
\end{abstract}




\section{TABLE OF CONTENTS}

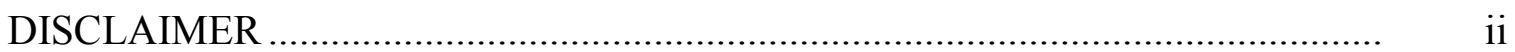

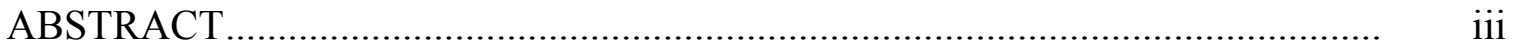

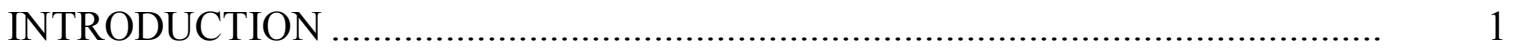

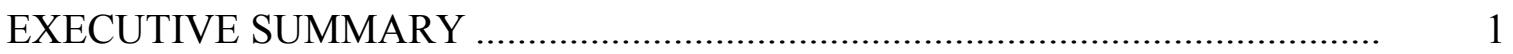

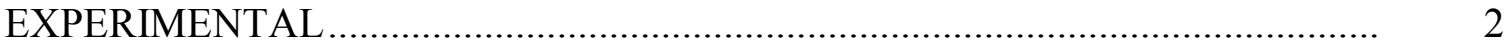

RESULTS AND DISCUSSION ................................................................ 2

Task 1: Formulation and Development of Solution Scheme ............................... 2

Mass Conservation Equation ................................................................. 2

Task 2: Formulation and Implementation of Chemical Module........................... 3

Polymer physical property relationships ................................................. 3

Polymer adsorption ..............................................................................

Polymer solution viscosity ..................................................................

Inaccessible pore volume ..................................................................

Permeability reduction .......................................................................

Solution procedure for fully implicit polymer module ............................. $\quad 7$

Automatic time step routine....................................................................

Task 3: Validation and Application ..................................................................

Polymer flooding using fully implicit formulation ....................................

3-D field-scale surfactant/polymer flooding ............................................ 10

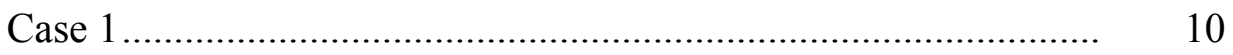

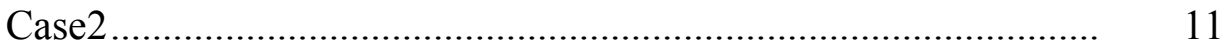

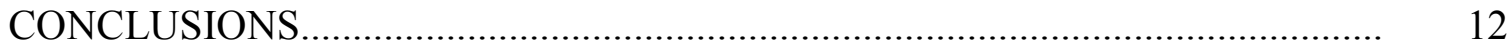

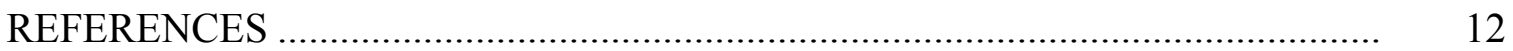




\section{LIST OF TABLES}

Page

Table 3.1. Input parameters for Case 1

14

Table 3.2. Input parameters for Case 2

14 


\section{LIST OF FIGURES}

Page

Fig. 3.1. Polymer concentration from GPAS and UTCHEM (constant rate injection) 15

Fig. 3.2. Water saturation from GPAS and UTCHEM (constant rate injection) 15

Fig. 3.3. Pressure profile from GPAS and UTCHEM (constant rate injection) 16

Fig. 3.4. Polymer concentration profile from GPAS and UTCHEM (constant pressure $\begin{array}{ll}\text { injection) } & 16\end{array}$

Fig. 3.5. Water saturation from GPAS and UTCHEM (constant pressure injection) 17

Fig. 3.6. Comparison of 2-D polymer concentrations for GPAs and UTCHEM 17

Fig. 3.7. 1-D polymerflood simulations using different number of processors 18

Fig. 3.8. Permeability profile 18

Fig. 3.9. Injection rate and cumulative fluid injected for Case 2

Fig. 3.10. Oil production rate and cumulative oil recovery for Case 2

Fig. 3.11. Cumulative oil recovery for Case 2. 20

Fig. 3.12. Surfactant concentration history for Case 2

Fig. 3.13. Surfactant concentration distribution at the end of chemical slug of $\begin{array}{ll}0.1 \mathrm{PV}(\text { Case 1) } & 21\end{array}$

Fig. 3.14. Oil saturation distribution during postwater flush at $0.5 \mathrm{PV}$ (Case 1) 21

Fig. 3.15. Well locations for test Ccase 2

Fig. 3.16. Parallel performance speed up for Ccase 2 


\section{INTRODUCTION}

In this report, we will detail our progress on Tasks 1 through 3 for the first half of the third year of the project. We have continued to test the parallel capability and efficiency of the code on larger problems. We made more simulations with the recently added explicit surfactant/polymer model. We formulated and implemented a fully implicit polymer module in GPAS. We have successfully compared the explicit and fully implicit polymer implementation in GPAS.

\section{EXECUTIVE SUMMARY}

The premise of this research is that a general-purpose reservoir simulator for several improved oil recovery processes can and should be developed so that highresolution simulations of a variety of very large and difficult problems can be achieved using state-of-the-art algorithms and computers. Such a simulator is not currently available to the industry. The goal of this proposed research is to develop a newgeneration chemical flooding simulator that is capable of efficiently and accurately simulating oil reservoirs with at least a million gridblocks in less than one day on massively parallel computers. Task 1 is the formulation and development of solution scheme, Task 2 is the implementation of the chemical module, and Task 3 is validation and application. We have made significant progress on all three tasks and we are on schedule on both technical and budget. In this report, we will detail our progress on Tasks 1 through 3 for the first six months of the second year of the project.

We previously reported on the formulation, implementation, and validation of the surfactant, polymer, and tracer species to the general purpose adaptive simulator (GPAS). The formulation was based on a hybrid approach where the mass conservation equations for hydrocarbon are solved implicitly where the aqueous species mass balances are solved explicitly using an updated phase fluxes, saturations, and densities. To take advantage of the larger time steps with the fully implicit formulation to reduce the simulation time, we have developed a fully implicit module of polymer flooding with the relevant physical properties. A few test cases were run to validate the formulation and implementation of polymer component in GPAS. 


\section{EXPERIMENTAL}

This project does not include an experimental component.

\section{RESULTS AND DISCUSSION}

\section{Task 1: Formulation and Development of Solution Scheme}

The effort on this task was directed towards the formulation of fully implicit polymer flooding module in GPAS.

\section{Mass Conservation Equation}

The mass balance equations for hydrocarbons species assuming no physical dispersion and mass transfer with the water phase are as follows:

$$
\mathrm{V}_{\mathrm{b}} \phi \frac{\partial \mathrm{N}_{\mathrm{i}}}{\partial \mathrm{t}}-\mathrm{V}_{\mathrm{b}} \nabla \cdot\left[\sum_{\mathrm{j}=2}^{3} \zeta_{\mathrm{j}} \lambda_{\mathrm{j}} \mathrm{x}_{\mathrm{ij}}\left(\nabla \mathrm{P}_{\mathrm{j}}-\gamma_{\mathrm{j}} \nabla \mathrm{D}\right)\right]-\mathrm{q}_{\mathrm{i}}=0 \quad \mathrm{i}=1, \ldots \mathrm{nc}
$$

where $\mathrm{N}_{\mathrm{i}}$ is the number of hydrocarbon moles per pore volume, $\mathrm{V}_{\mathrm{b}}$ is the bulk volume, $\lambda_{\mathrm{j}}$ is the relative mobility for phase $\mathrm{j}$ where $\mathrm{j}=2$ is the oil phase and $\mathrm{j}=3$ is the gas phase, $\zeta_{j}$ is the molar density of phase $j$, and $x_{i j}$ is the fraction of hydrocarbon $i$ in phase $j$, and $\gamma_{j}$ is the specific density of phase $\mathrm{j}, \mathrm{q}_{\mathrm{i}}$ is the number of hydrocarbon moles produced or injected .

The mass balance equation for water component is

$$
\mathrm{V}_{\mathrm{b}} \phi \frac{\partial \mathrm{N}_{\mathrm{w}}}{\partial \mathrm{t}}-\mathrm{V}_{\mathrm{b}} \nabla \cdot\left[\zeta_{1} \lambda_{1}\left(\nabla \mathrm{P}_{1}-\gamma_{1} \nabla \mathrm{D}\right)\right]-\mathrm{q}_{\mathrm{w}}=0
$$

where $\mathrm{N}_{\mathrm{w}}$ is the number of water moles per pore volume, $\lambda_{1}$ is the relative mobility for water phase $(j=1), \zeta_{1}$ is the molar density of water, and $\gamma_{1}$ is the specific density of water phase, $\mathrm{q}_{\mathrm{w}}$ is the number of water moles produced or injected . 
The mass balance equation for polymer component is

$$
\mathrm{V}_{\mathrm{b}} \phi \frac{\partial \mathrm{W}_{\mathrm{p}}}{\partial \mathrm{t}}-\mathrm{V}_{\mathrm{b}} \nabla \cdot\left[\zeta_{1} \lambda_{1} \frac{\mathrm{W}_{\mathrm{p}, 1}}{\mathrm{~N}_{\mathrm{w}}}\left(\nabla \mathrm{P}_{1}-\gamma_{1} \nabla \mathrm{D}\right)\right]-\mathrm{q}_{\mathrm{p}}=0
$$

where $\mathrm{W}_{\mathrm{p}}$ is the mass of polymer per pore volume, $\mathrm{W}_{\mathrm{p}, 1}$ is the mass fraction of polymer in aqueous phase, and $\mathrm{q}_{\mathrm{p}}$ is the mass of polymer produced or injected .

The assumptions in deriving the mass balance equation for polymer are as follow:

- Physical dispersion is neglected

- Polymer stays in the aqueous phase and does not partition into oil or gas hydrocarbon phases.

- Polymer does not undergo chemical reactions

- Polymer does not change volume and density of the aqueous phase

\section{Task 2: Formulation and Implementation of Chemical Module}

\section{Polymer physical property relationships}

The polymer physical properties are based on those used in UTCHEM. These relationships have been carefully tested against experimental and published data and are used in most commercial simulators as well. Here is the list of polymer properties implemented in GPAS that are similar to those implemented in the explicit chemical module.

- Adsorption

- Viscosity

- Inaccessible pore volume

- Permeability reduction factor 


\section{Polymer Adsorption}

The retention of polymer molecules in permeable media is caused by the adsorption onto solid surfaces and trapping within small pores and is modeled in GPAS as a function of salt concentration and polymer concentration as follows:

$$
\begin{aligned}
& \hat{\mathrm{C}}_{\mathrm{p}}=\min \left(\widetilde{\mathrm{C}}_{\mathrm{p}}, \frac{\mathrm{a}_{\mathrm{p}}\left(\widetilde{\mathrm{C}}_{\mathrm{p}}-\hat{\mathrm{C}}_{\mathrm{p}}\right)}{1+\mathrm{b}_{3}\left(\widetilde{\mathrm{C}}_{\mathrm{p}}-\hat{\mathrm{C}}_{\mathrm{p}}\right)}\right) \\
& \mathrm{a}_{\mathrm{p}}=\left(\mathrm{a}_{\mathrm{p} 1}+\mathrm{a}_{\mathrm{p} 2} \mathrm{C}_{\mathrm{SE}}\right)
\end{aligned}
$$

Where the overall surfactant concentration $\left(\widetilde{\mathrm{C}}_{\mathrm{p}}\right)$ is normalized by the water concentration $\left(\mathrm{C}_{1}\right)$. The adsorption model parameters $\mathrm{a}_{\mathrm{p} 1}, \mathrm{a}_{\mathrm{p} 2}$, and $\mathrm{b}_{\mathrm{p}}$ are found by matching laboratory surfactant adsorption data. $\mathrm{C}_{\mathrm{SE}}$ is the effective salinity that is the concentration of salt in the aqueous phase.

\section{Polymer Solution Viscosity}

The aqueous phase viscosity is a function of polymer concentration and pure water viscosity as follows:

$$
\mu_{\mathrm{p}}=\mu_{\mathrm{w}}\left[1+\left(\mathrm{A}_{\mathrm{p} 1} \mathrm{C}_{\mathrm{p} 1}+\mathrm{A}_{\mathrm{p} 1} \mathrm{C}_{\mathrm{p} 1}^{2}+\mathrm{A}_{\mathrm{p} 1} \mathrm{C}_{\mathrm{p} 1}^{3}\right) \mathrm{C}_{\mathrm{SE}}^{\mathrm{s}_{\mathrm{p}}}\right\rfloor
$$

where $\mu_{\mathrm{w}}$ is the water viscosity, $\mathrm{A}_{\mathrm{p} 1}, \mathrm{~A}_{\mathrm{P} 2}$, and $\mathrm{A}_{\mathrm{p} 3}$ are the model parameters, and $\mathrm{C}_{\mathrm{p} 1} \mathrm{~s}$ the polymer concentration in the aqueous phase $s_{p}$ is the exponent of salinity dependence of polymer solution viscosity.

\section{Inaccessible Pore Volume}

High molecular weight polymer molecules usually flow faster than the solvent or smaller non-interacting components in the solution since the size of the polymer coil can 
approach the size of a pore throat in many reservoir rocks, which results in wall exclusion effects among other phenomena. This faster flow of polymer molecules can result in socalled inaccessible pore volume, which is commonly used to mean both pores that are inaccessible and also the higher velocity in accessible pores due to the large size of the polymer molecule lumped together.

Polymer inaccessible pore volume phenomenon depends on (1) characteristics of the porous media, especially its permeability, (2) polymer and electrolyte type, (3) polymer concentration, and (4) aqueous phase saturation.

The literature cites cases where as much as $30 \%$ of the pore volume may be inaccessible pore volume. The inaccessible pore volume is modeled by reducing the porosity in the component mass balance equation for polymer by multiplying with the input parameter $\mathrm{E}_{\mathrm{phi}}$ defined below. The resulting effect is a faster polymer velocity than the velocity of a reference aqueous phase tracer.

Some of the possible reasons for the inaccessible pore volume effect as follows:

- Pore-wall exclusion: Pore-wall exclusion of the polymer molecules relative to the very small molecules such as water that make up the polymer solvent

- Rheological properties: the shear rate is considerably different in different parts of a given pore and also from pore to pore.

- Amount and type of retention: an adsorbed polymer coil effectively excludes a certain volume of the pore to further penetration by a mobile polymer coil.

A porosity correction factor is used to model the lumped effect. The effective porosity for the polymer is modeled as 


$$
\varphi_{\text {polymer }}=\varphi_{\text {actual }} \mathrm{E}_{\mathrm{phi}}
$$

where $\mathrm{E}_{\mathrm{phi}}$ is the effective porosity factor to be multiplied with the actual porosity to get the apparent porosity for the polymer. This modified porosity is used in the aqueous species conservation equation (Equation 3) resulting in a faster velocity of polymer molecules.

\section{Permeability Reduction}

Some water-soluble polymer solutions reduce both the mobility of the aqueous phase in low to moderate permeability rocks. This is because the polymer adsorb on the porous medium, or is trapped in small pore throats, or is entangled in small pores or all of these in some cases, and thus reduces the aqueous mobility further than that caused by the increase in aqueous viscosity alone. This effect is called permeability reduction and can be significant for polymers such as hydrolyzed polyacrylamide that is used in most polymer flood field applications, but typically is not significant for biopolymers such as xanthan gum. The permeability to oil is not reduced, so the effect on the fractional flow of oil is beneficial i.e. relatively more oil than water flows.

The permeability reduction is modeled by the permeability reduction factor, $\mathrm{R}_{\mathrm{k}}$ defined as the ratio of the effective permeability of water to the effective permeability of polymer. The assumptions made for the model are:

- The polymer phase alone is affected by this reduction in permeability

- The permeability reduction is irreversible

The equation used for calculating the permeability reduction factor is 


$$
\mathrm{R}_{\mathrm{k}}=1.0+\frac{\left(\mathrm{R}_{\mathrm{k}, \max }-1.0\right) \mathrm{b}_{\mathrm{rk}} \mathrm{C}_{41}}{1.0+\mathrm{b}_{\mathrm{rk}} \mathrm{C}_{41}}
$$

where

$$
\mathrm{R}_{\mathrm{k}, \max }=\min \left\{\left[1-\frac{\mathrm{C}_{\mathrm{rk}}\left(\mathrm{A}_{\mathrm{pl}} \mathrm{C}_{\mathrm{SEP}}^{\mathrm{S}_{\mathrm{p}}}\right)^{1 / 3}}{\left(\frac{\sqrt{\mathrm{k}_{\mathrm{x}} \mathrm{k}_{\mathrm{y}}}}{\varphi}\right)^{1 / 2}}\right]^{-4}, 10\right\}
$$

and $\mathrm{b}_{\mathrm{rk}}$ and $\mathrm{C}_{\mathrm{rk}}$ are the input parameters.

The permeability reduction is modeled in the subroutine PROP. The keyword IPERMRED in the input file will activate the permeability reduction physical model. The parameters $\mathrm{b}_{\mathrm{rk}}, \mathrm{C}_{\mathrm{rk}}$, and $\mathrm{A}_{\mathrm{pl}}$ are input parameters. The mobility of the aqueous phase containing the polymer is then reduced by the permeability reduction factor.

\section{Solution procedure for fully implicit polymer module}

The computational procedure for the fully implicit polymer flooding module are outlines below:

1. Initialize pressure and composition in each gridblock

2. Compute phase properties based on the initial composition such as phase densities, phase viscosities, and relative Permeabilities

3. Linearize the governing equations in terms of the independent variables $N_{i}, N_{w}$, $\mathrm{W}_{\mathrm{p}}$ and Pressure, $\mathrm{P}$

4. Compute elements of Jacobian 
5. Solve the system of linear equations simultaneously for all gridblocks using Newton method and linear solver PETSc.

6. Calculate polymer adsorption and permeability reduction factor

7. Update phase densities, viscosities and relative permeabilities

8. Check for convergence

\section{Automatic time step routine}

A new automatic time step control was added which is more stable and more efficient compared to the one already implemented in the code based on the number of Newtonian iterations. The new implementation is based on the maximum change in pressure, phase saturation, and molar concentration of each species. The formulation is described as below

$$
\Delta \mathrm{t}^{\mathrm{n}+1}=\Delta \mathrm{t}^{\mathrm{n}}\left[\frac{(1+\omega) \eta_{\mathrm{i}}}{\delta_{\mathrm{i}}+\omega \eta_{\mathrm{i}}}\right]_{\text {min overall gridblocks }}
$$

where $\omega$ is the tuning factor and is between a value of zero and one, $\eta_{\mathrm{i}}$ is the maximum relative change for each variable as an input parameter, and $\delta_{\mathrm{i}}$ is the computed relative change of the variable in gridblock i during the time step $\Delta$ t. The value of the bracket in Equation 10 is different depending on the variables (pressure, saturation, and species molar concentration) and the minimum will be used in the time step selection. Additional input parameters added for the time step control option 2 (TIME_CONTROL $=2)$ are listed as below.

TUNE : tuning factor with a value between 0 and 1

DCMAX : maximum relative change of molar concentration

DPMAX = maximum relative change of pressure

DSPMAX = maximum relative change of saturation 
DELTIM = initial time step in days

DTIMMAX $=$ maximum time step, days

DTIMMIN = minimum time step, days

Several simulations were performed to test and verify the time step routine and its implementation in GPAS.

\section{Task 3: Validation and Application}

\section{Polymer flooding using fully implicit formulation}

To validate the correctness of the fully implicit polymer formulation and implementation in GPAS, we have made comparisons of the results against our existing IMPEC simulator, UTCHEM.

A few test cases were run to validate the formulation and implementation of implicit polymer component in GPAS. One-dimensional polymer flood cases were simulated with GPAS and the results were compared with UTCHEM simulation results. The simulation domain consisted of $400 \mathrm{ft}$ in the $\mathrm{x}$ direction, $1 \mathrm{ft}$ in y direction, and $1 \mathrm{ft}$ in the $\mathrm{z}$ direction. $40 \times 1 \times 1$ gridblocks were used. The initial water saturation was 0.7 with the residual oil saturation of 0.3 . The oil phase is a single component decane. Water with $0.05 \mathrm{wt} \%$ polymer was injected at a constant flow rate. The profile of normalized polymer concentration is shown in Fig. 3.1. There is an excellent agreement between the results of GPAS and UTCHEM. Water saturation profile is shown in Fig. 3.2. The effect of polymer viscosity on the injection pressure is shown in Fig. 3.3. 1-D simulations were performed with constant pressure injection well and the results are favorable compared to those from UTCHEM simulator as shown in Figs. 3.4.and 3.5.

We also performed 2-D simulations of polymer flood with GPAS and compared with UTCHEM. A 10x10 areal grid was set up. The reservoir was initially saturated with water and residual oil saturation of 0.5 . A $0.05 \mathrm{wt} \%$ polymer solution was injected. An excellent agreement of polymer concentration profile between UTCHEM and GPAS is shown in Fig. 3.6. 
To ensure that the correctness of the implementation for the multiple processor runs, we have repeated the 1-D polymer flood simulation on two and four processors and the result $\mathrm{s}$ are identical as shown in Fig. 3.7.

\section{3-D field-scale surfactant/polymer simulation}

Case 1: The 3-D reservoir simulated in this example is an idealization of a light oil midcontinent US sandstone reservoir. This reservoir is assumed to be waterflooded to an initial oil saturation of about 0.30 . Since the assumed waterflood residual saturation is 0.25 , most of the oil production after the start of the chemical flood can be considered tertiary oil recovery. The reservoir is $3500 \mathrm{ft}$ deep and $140 \mathrm{ft}$ thick. The oil viscosity is $7.8 \mathrm{cp}$. The permeability distribution was generated by a stochastic method with a geomtric mean of about $50 \mathrm{md}$ and a Dykstra-Parsons coefficient of 0.80 . A spherical variogram and a log-normal permeability distribution were used. Correlation lengths of $660 \mathrm{ft}$ in the $\mathrm{x}$ and $\mathrm{y}$ directions and $28 \mathrm{ft}$ in the $\mathrm{z}$ direction were used. Figure 3.8 shows the permeability field. The vertical permeability was $50 \mathrm{md}$. A uniform porosity of 0.136 was used. The well arrangement is a quarter symmetry element of a forty-acre five-spot well pattern. The injection and production wells were located in the opposite corners and perforated across the entire reservoir thickness. Both wells are operating at constant bottom hole pressure. The reservoir and fluid properties are given in Table 3.1.

A chemical slug containing 0.05 volume fraction surfactant and $0.05 \mathrm{wt} \%$ (500 ppm) polymer was injected followed by a polymer drive of the same concentration and lastly a water drive. The salinity was constant and equal to $0.5 \mathrm{meq} / \mathrm{ml}(19,500 \mathrm{ppm})$, a value below the optimum salinity i.e. in the Type II(-) region. No alcohol was needed with this surfactant. The surfactant/polymer slug was injected for 400 days (about 0.13 $\mathrm{PV}$ ) and polymer drive was injected for 600 days (about $0.22 \mathrm{PV}$ ).

The injection rate was about $500 \mathrm{STB} / \mathrm{d}$ during the chemical slug and then increased to about $2200 \mathrm{STB} / \mathrm{d}$ during the water injection since it is less viscous (Fig. 3.9). The time vs. pore volume relationship is shown on the secondary axis. Figure 3.10 shows the rate of oil production and cumulative oil produced. Oil rate starts fairly low at less than $20 \mathrm{STB} / \mathrm{d}$ during the chemical slug injection and it peaks at about $140 \mathrm{STB} / \mathrm{d}$ 
during the water drive. The cumulative oil recovered as a fraction of remaining oil in place is about $22 \%$ (Fig. 3.11). The produced surfactant concentration peaks at about 0.007 volume fraction (Fig. 3.12). Several cross sections of the surfactant concentration at the end of chemical slug of $0.10 \mathrm{PV}$ and oil saturation during the water drive at about $0.5 \mathrm{PV}$ are shown in Figs. 3.13 and 3.14. Oil saturation is reduced to 0.05 from the initial value of 0.30 .

The intention here was not to optimize the chemical flood for this reservoir, but simply to show a realistic simulation of a chemical flood with GPAS. A better chemical flood design (Wu et al., 1996) for this reservoir included horizontal wells.

Case 2. Many previous test runs have been performed using the fully implicit EOS compositional model to simulate gas injection (Abate et al., 2001; Uetani et al., 2002). The case described next was setup to test the parallel performance of the simulator with the chemical model. An oil reservoir of dimensions $2400 \mathrm{ft} \times 2400 \mathrm{ft} \times 12 \mathrm{ft}$ having 13 wells in a five-spot pattern was simulated (Fig. 3.15). The numerical grid was 96x96x12 (110,592 gridblocks) in the $\mathrm{x}, \mathrm{y}$ and $\mathrm{z}$ directions, respectively. The fluid properties, relative permeability data and chemical parameters are the same as for Case 1. The reservoir was initialized at residual oil saturation and 900 psi pressure. The chemical slug injected in all the injection wells at a constant pressure of 1500 psi. The input data is summarized in Table 3.2 .

A Dell Power Edge 1750 cluster was used as the test platform. Each node is a dual processor Intel Xeon processor running at $3.06 \mathrm{GHz}$ having $2 \mathrm{~GB}$ RAM and $533 \mathrm{MHz}$ bus speed. The nodes are connected by a $100 \mathrm{Mbps}$ ethernet switch for communication. The cluster runs Red Hat Linux v9.0 with GNU C/C $\mathrm{C}^{++}$and Portland Group Fortran 77/90 compilers version 5.0, MPICH version 1.2.4, which is a portable implementation of the Message Passing Interface (MPI) from Argonne National Laboratory for parallel communication, and PETSc version 2.1.6 with incomplete LU preconditioner and Generalized Minimum Residual Algorithm (GMRES) solver.

Figure 3.16 shows the speedup of the run for 100 days of simulation time on two, four, and eight processors. The curve is normalized to the timing from the single 
processor run. The performance speedup is reduced with more processors because of the insufficient amount of computational task for each processor as the computational domains becomes smaller.

A different indicator of parallel performance would be to keep the problem size per processor constant and increase the number of processors. Also, the use of layered or stochastic permeability fields affects the performance as reported in an earlier paper (Wang et al., 1999) for the EOS compositional model. We plan to perform larger surfactant/polymer floods with stochastic permeability fields and with a larger number of gridblocks.

\section{CONCLUSIONS}

In this report, we gave our progress on Tasks 1 through 3 for the first half of the third year of the project. We formulated and implemented a fully implicit polymerflooding module to take advantage of larger time steps. Several simulations were performed to validate the formulation and implementation in GPAS. Preliminary simulation results indicate the larger time steps are possible with the fully implicit formulation compared to the explicit model implemented previously in GPAS. We have implemented a new automatic time step routine that is more stable and results in larger time steps as compared to the earlier implementation based on the number of Newton iteration. Surfactant/polymer simulations were performed with more than 100,000 gridblocks in a parallel environment with results indicating a good scalability of the simulator.

\section{REFERENCES}

Abate, J.M., P. Wang and K. Sepehrnoori, "Parallel Compositional Reservoir Simulation on a Cluster of PCs," International Journal of High Performance Computing Applications, Spring 2001.

Uetani T., B. Guler, and K. Sepehrnoori, "Reservoir Simulation on High Performance Clusters," presented at the Sixth World Multiconference on Systematics, Cybernetics, and Informatics, Orlando, FL, 14-18 July, 2002. 
Wang, P., S. Balay, K. Sepehrnoori, J. Wheeler, J. Abate, B. Smith and G.A. Pope: "A Fully Implicit Parallel EOS Compositional simulator for Large Scale Reservoir Simulation," paper SPE 51885 presented at the SPE $15^{\text {th }}$ Reservoir Simulation Symposium, Houston, Texas, 14-17 February, 1999.

Wu, W., A. Vaskas, M. Delshad, G.A. Pope, and K. Sepehrnoori: "Design and Optimization of Low-Cost Chemical Flooding," paper SPE/DOE 35355 presented at the 1996 SPE/DOE Tenth Symposium on Improved Oil recovery, Tulsa, OK, 21-24 April 1996. 
Table 3.1: Input parameters for Case 1

\begin{tabular}{|c|c|}
\hline Property & Value \\
\hline Reservoir size & $660 \mathrm{ft} \times 660 \mathrm{ft} \times 140 \mathrm{ft}$ \\
\hline Reservoir gridblock size & $66 \mathrm{ft} \times 66 \mathrm{ft} \times 28 \mathrm{ft}$ \\
\hline No. of gridblocks & $11 \times 11 \times 5$ \\
\hline Matrix permeability & $\begin{array}{l}\text { Stochastic, MDM method } \\
\text { using } \mathrm{V}_{\mathrm{DP}}=0.8, \mathrm{~K}_{\text {avg }}=50 \mathrm{mD} \\
\text { (geom), } 180 \mathrm{mD} \text { (arithmetic) }\end{array}$ \\
\hline Matrix porosity & 0.136 \\
\hline Initial water saturation & 0.7 \\
\hline Water viscosity & $0.7 \mathrm{cp}$ \\
\hline Oil viscosity & $7.78 \mathrm{cp}$ \\
\hline Polymer viscosity parameters & $81,2500,2700$ \\
\hline \multicolumn{2}{|l|}{ Surfactant properties } \\
\hline Heights of binodal curve & $0.016,0.01$ vol. fraction \\
\hline Salnity limits & $0.55,0.91 \mathrm{meq} / \mathrm{ml}$ \\
\hline $\mathrm{CMC}$ & 0.00006 vol. fraction \\
\hline Adsorption paramters & $1.0,0.5,1000$ \\
\hline Initial reservoir pressure & $900 \mathrm{psi}$ \\
\hline Injection pressure & $1500 \mathrm{psi}$ \\
\hline Production constraint (BHP) & $100 \mathrm{psi}$ \\
\hline Chemical slug injection time & 400 days \\
\hline Chemical slug composition & $\begin{array}{c}0.54 \mathrm{meq} / \mathrm{ml} \text { salt, } 0.05 \mathrm{vol} \% \\
\text { surfactant, } 0.05 \mathrm{wt} \% \\
\text { polymer, water }\end{array}$ \\
\hline Polymer drive injection time & 600 days \\
\hline Polymer drive composition & $\begin{array}{c}0.54 \mathrm{meq} / \mathrm{ml} \mathrm{salt}, 0.05 \mathrm{wt} \% \\
\text { polymer, water }\end{array}$ \\
\hline Post Flush & $0.54 \mathrm{meq} / \mathrm{ml}$ brine \\
\hline Simulation Time & 1500 days \\
\hline
\end{tabular}

Table 3.2: Input parameters for Case 2

\begin{tabular}{|l|c|}
\hline \multicolumn{1}{|c|}{ Property } & Value \\
\hline Reservoir size & $2400 \mathrm{ft} \times 2400 \mathrm{ft}$ x 96ft \\
\hline Reservoir gridblock size & $25 \mathrm{ft}$ x 25ft x 8ft \\
\hline No. of gridblocks & $96 \times 96$ x 12 \\
\hline Initial pressure & $900 \mathrm{psi}$ \\
\hline Injection rates & $1000 \mathrm{STB} /$ day \\
\hline Production pressure & $500 \mathrm{psi}$ \\
\hline Number of injection wells & 9 \\
\hline Number of production wells & 4 \\
\hline Well pattern & Five spot pattern \\
\hline
\end{tabular}




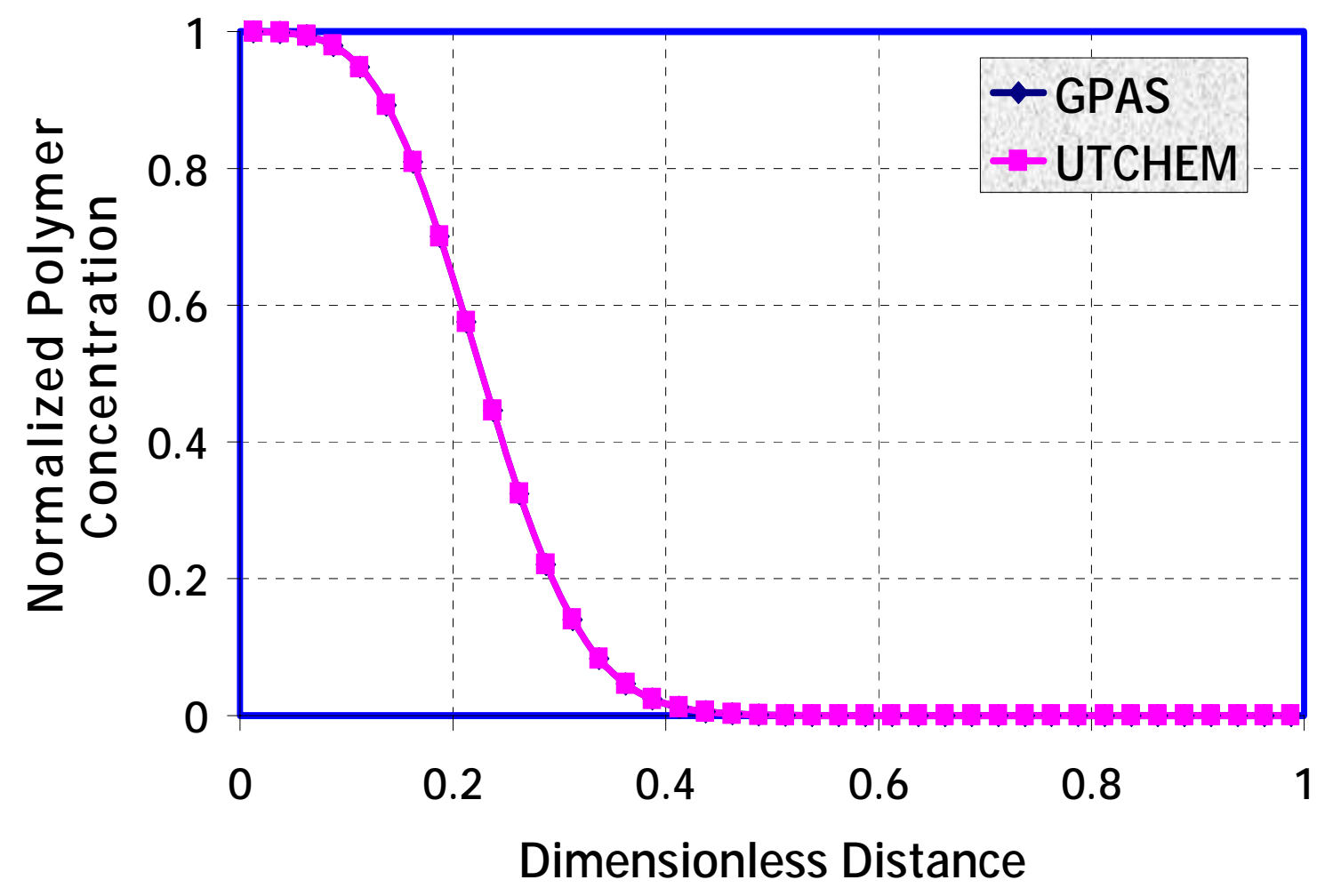

Fig. 3.1. Polymer concentration from GPAS and UTCHEM (constant rate injection)

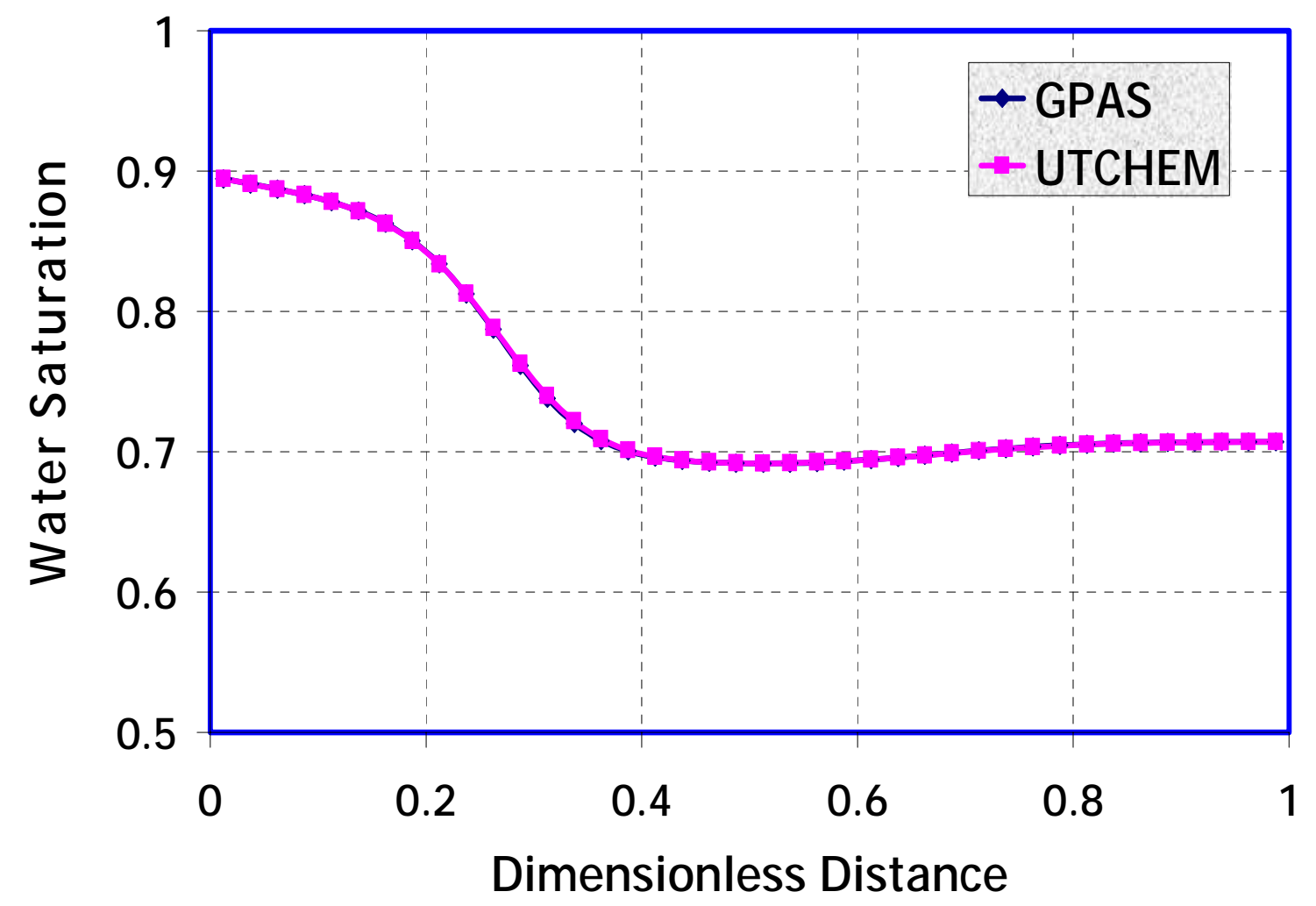

Fig. 3.2. Water saturation from GPAS and UTCHEM (constant rate injection) 


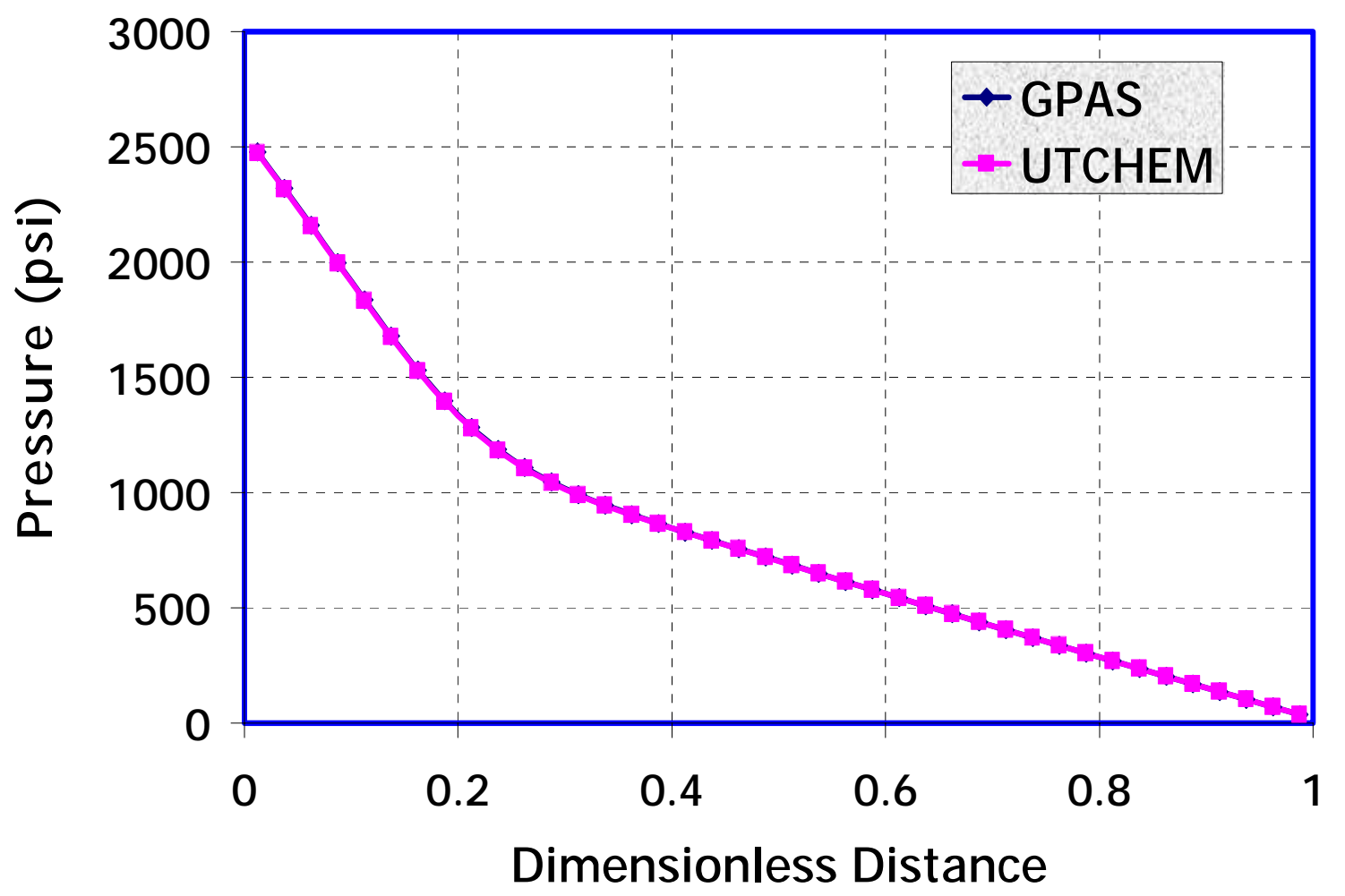

Fig. 3.3. Pressure profile from GPAS and UTCHEM (constant rate injection)

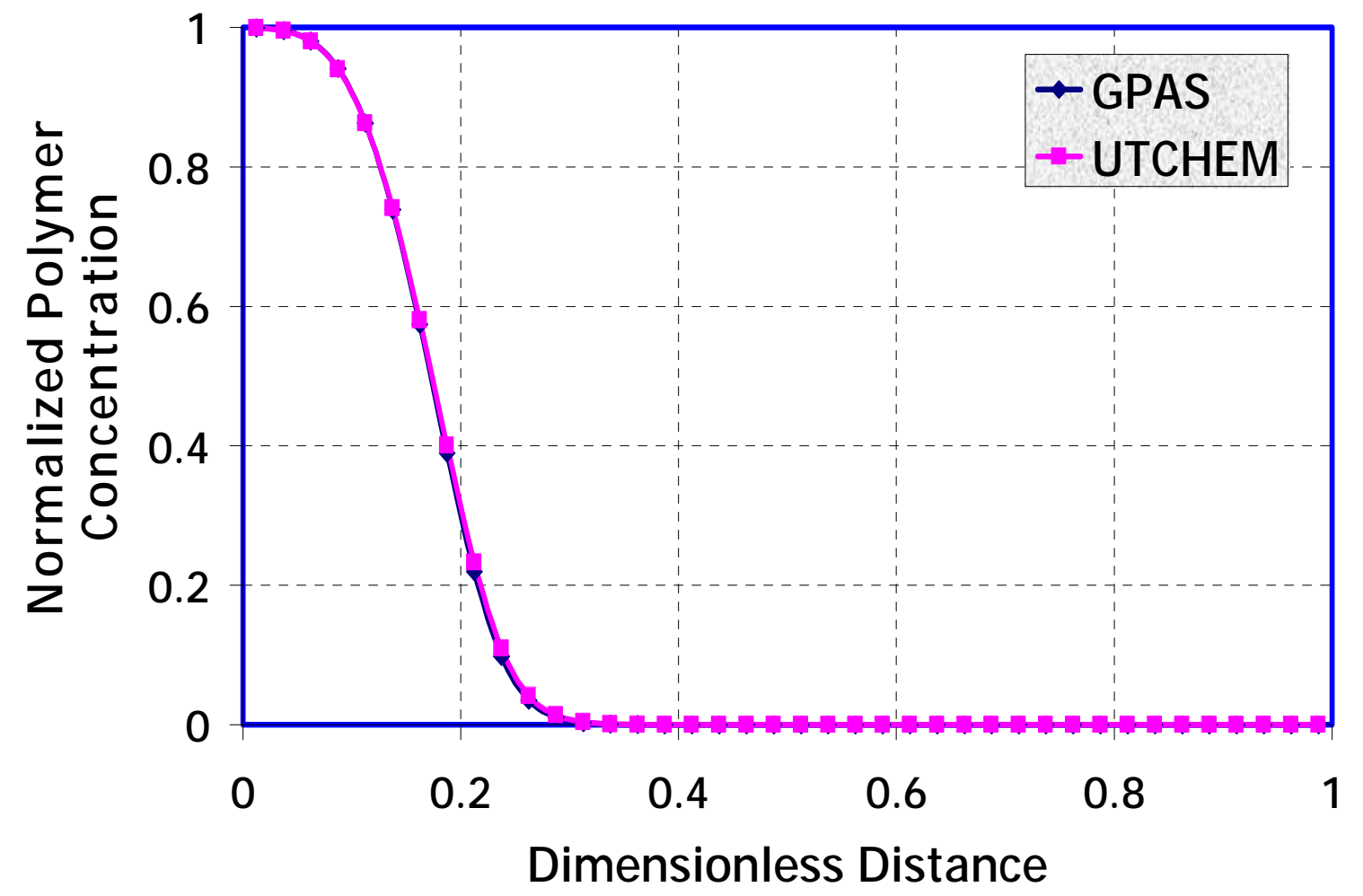

Fig. 3.4. Polymer concentration profile from GPAS and UTCHEM (constant pressure injection) 


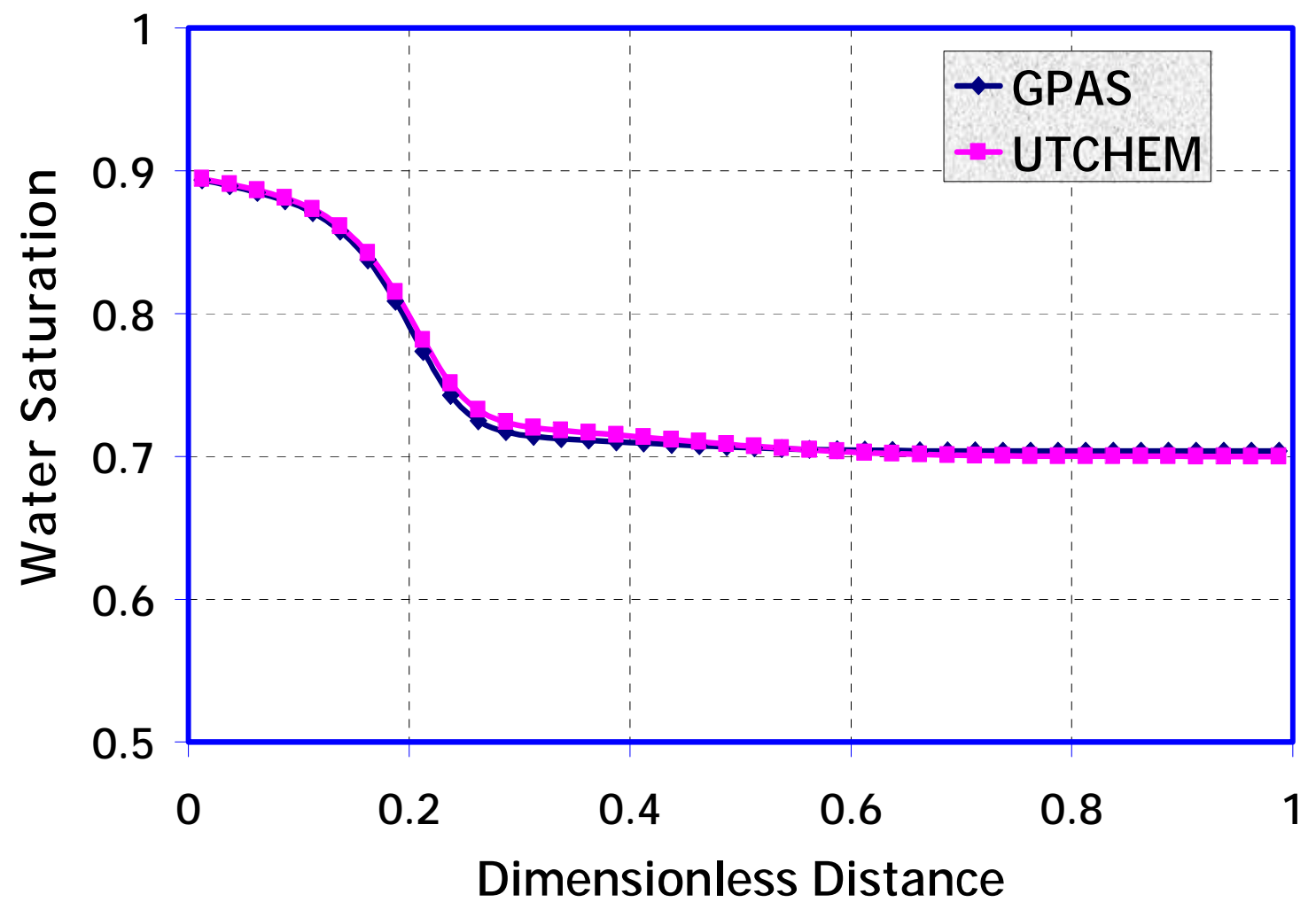

Fig. 3.5. Water saturation from GPAS and UTCHEM (constant pressure injection)

Normalized Polymer

Concentration

GPAS

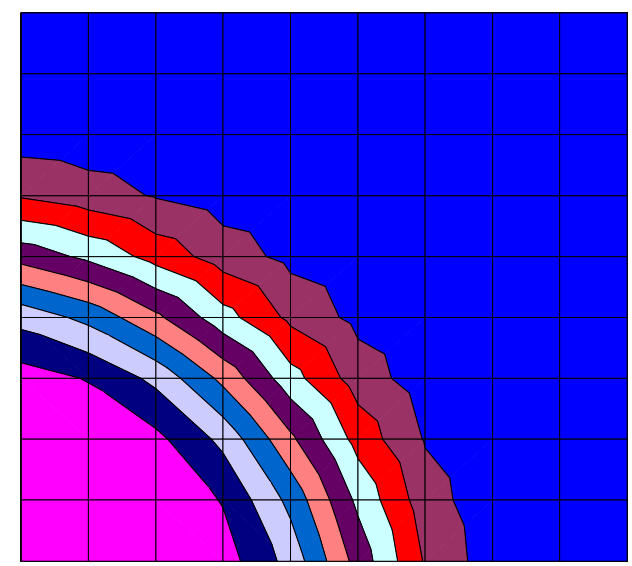

Fig. 3.6. Comparison of 2-D polymer concentrations for GPAs and UTCHEM
Normalized Polymer

Concentration

UTCHEM

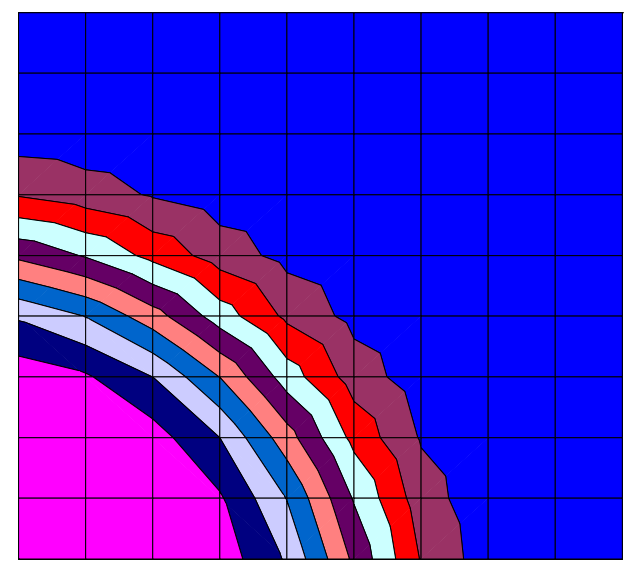

0.9-1

0 0.8-0.9

$\square$ 0.7-0.8

$\square$ 0.6-0.7

$\square$ 0.5-0.6

0.4-0.5

$\square$ 0.3-0.4

- 0.2-0.3

$\square$ 0.1-0.2

- 0-0.1 


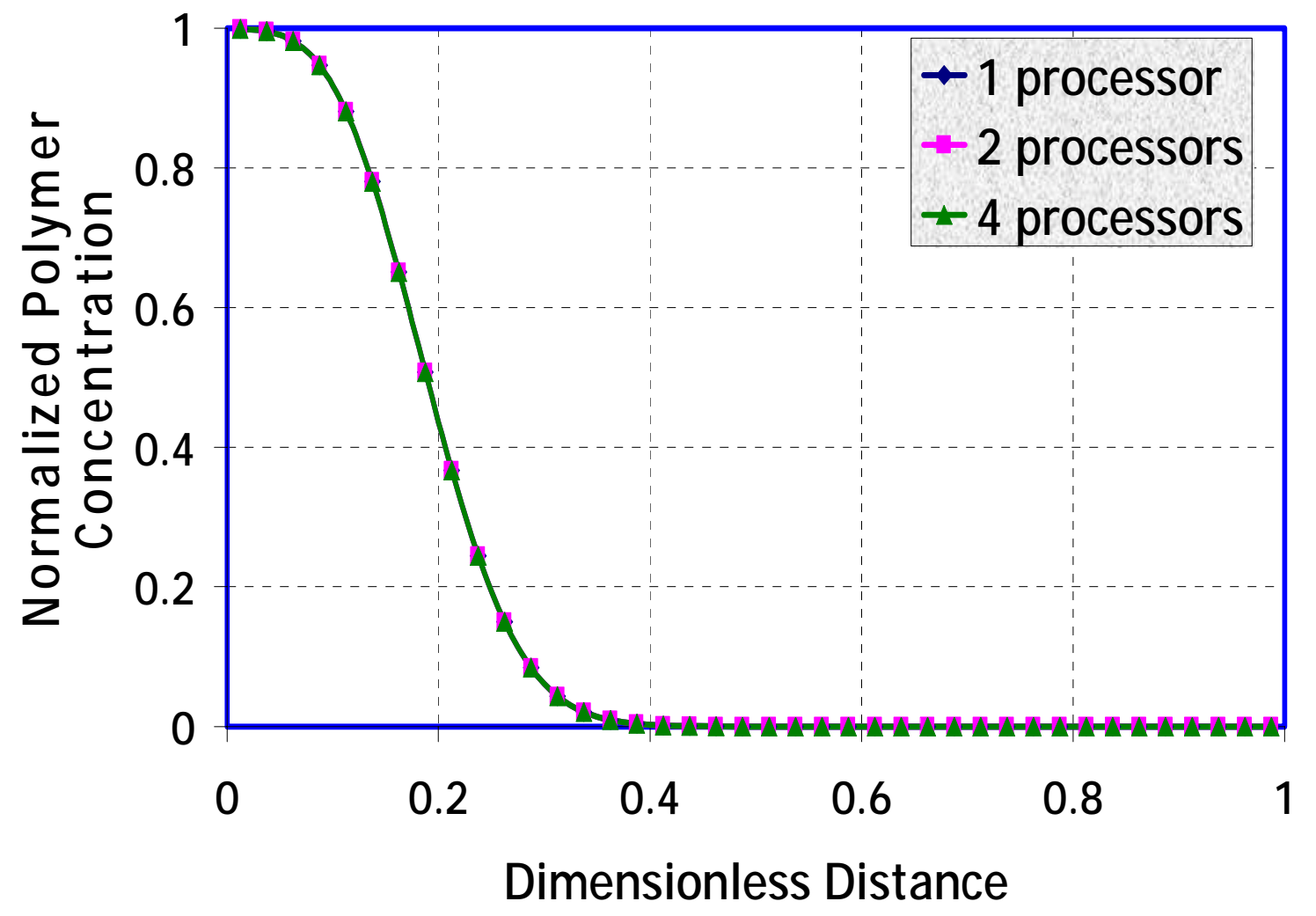

Fig. 3.7. 1-D polymerflood simulations using different number of processors

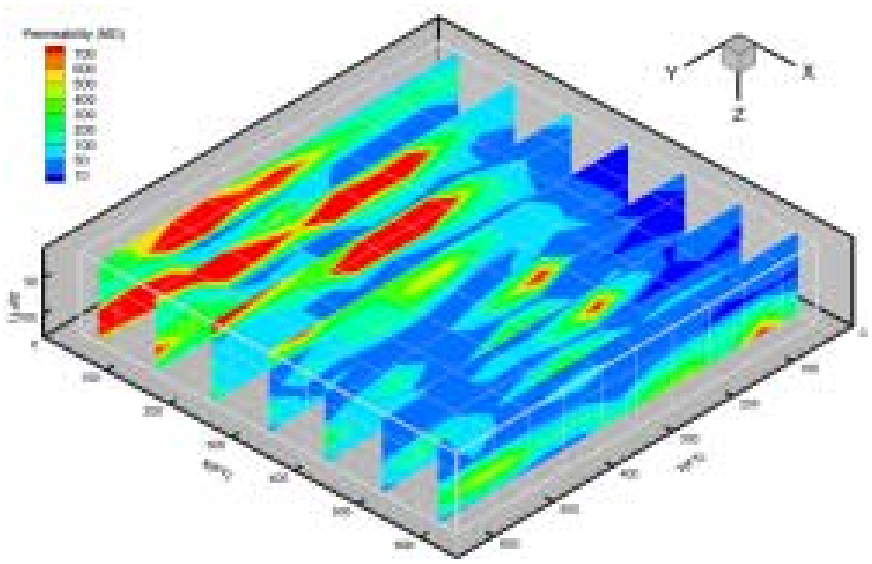

Fig. 3.8. Permeability profile 


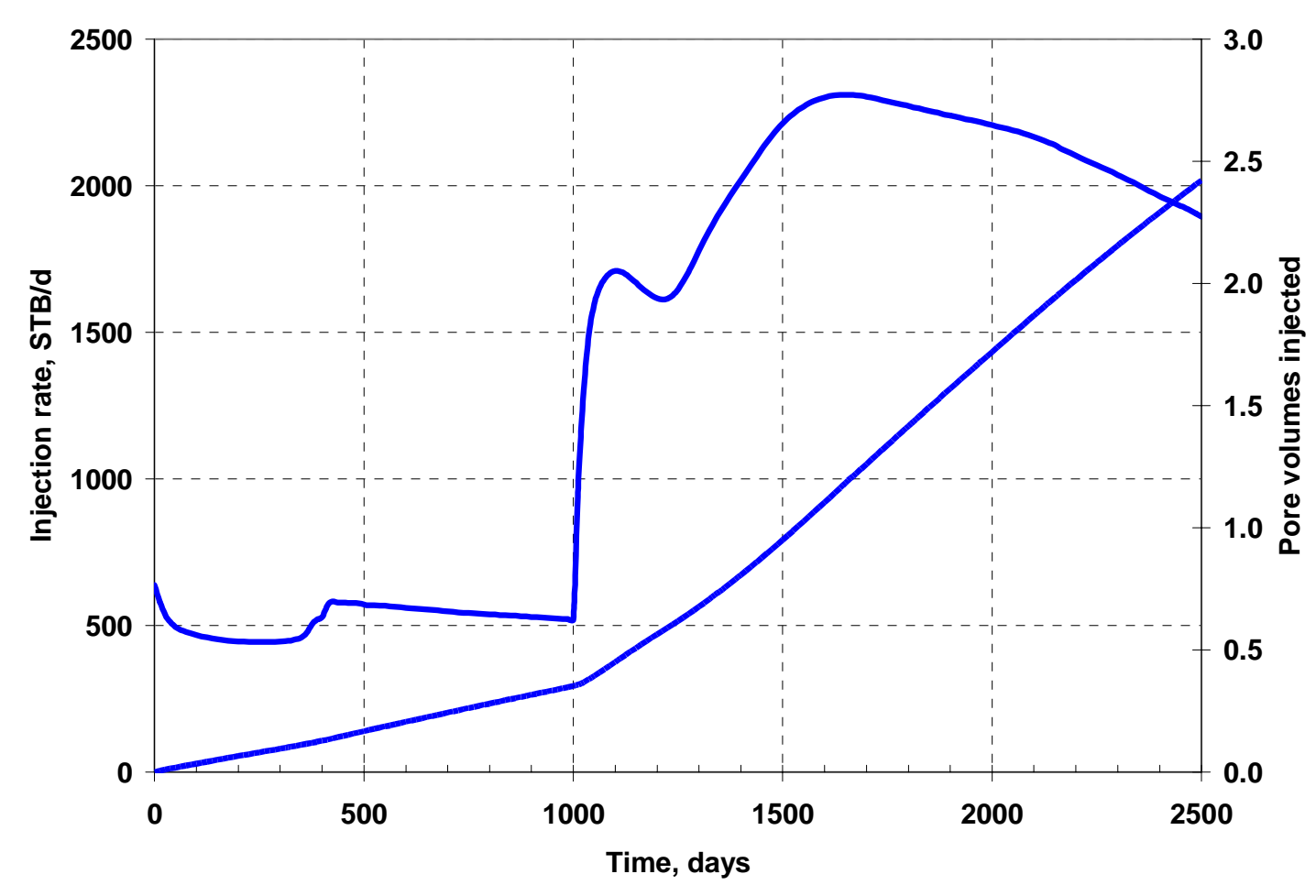

Fig. 3.9. Injection rate and cumulative fluid injected for Case 2

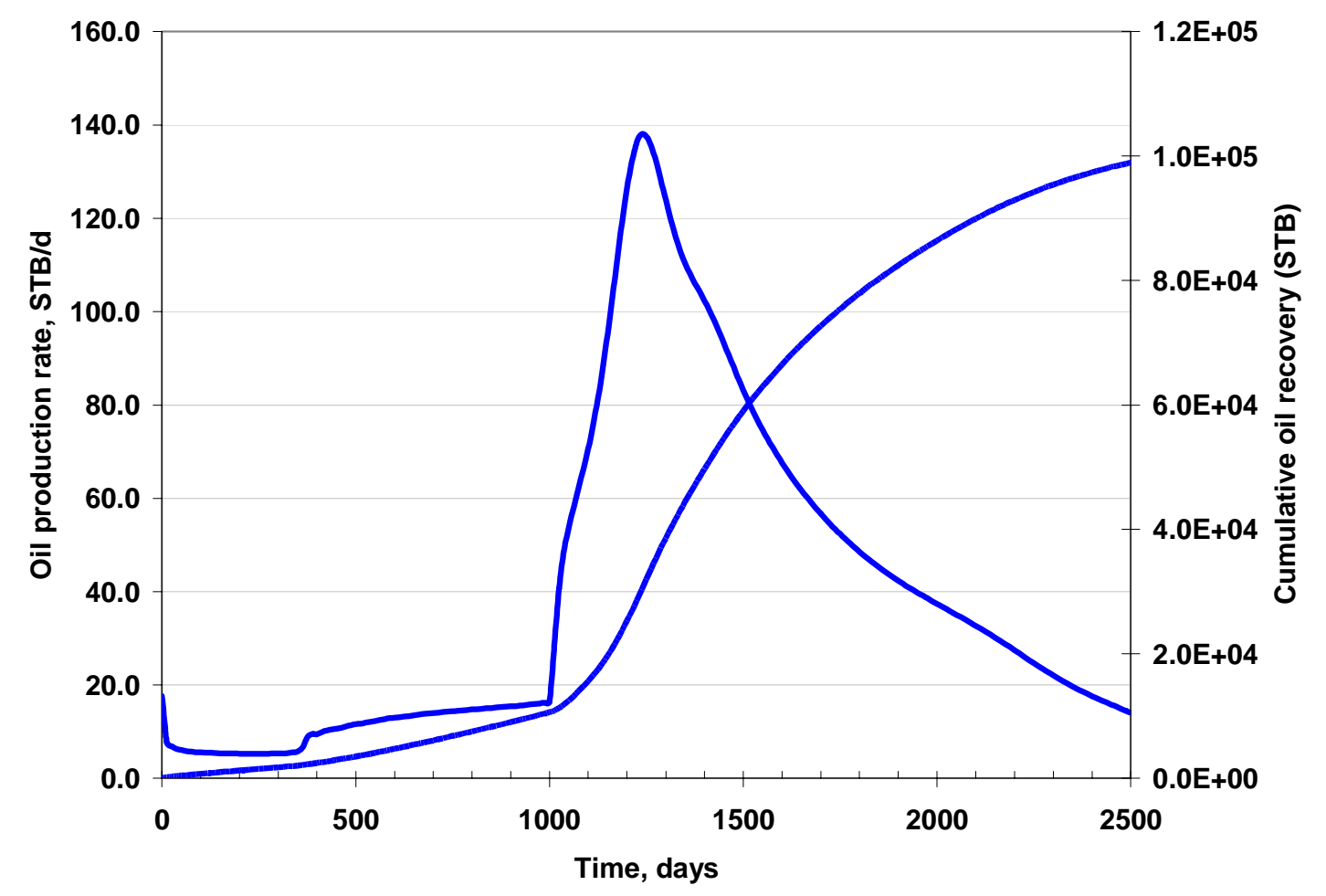

Fig. 3.10. Oil production rate and cumulative oil recovery for Case 2 


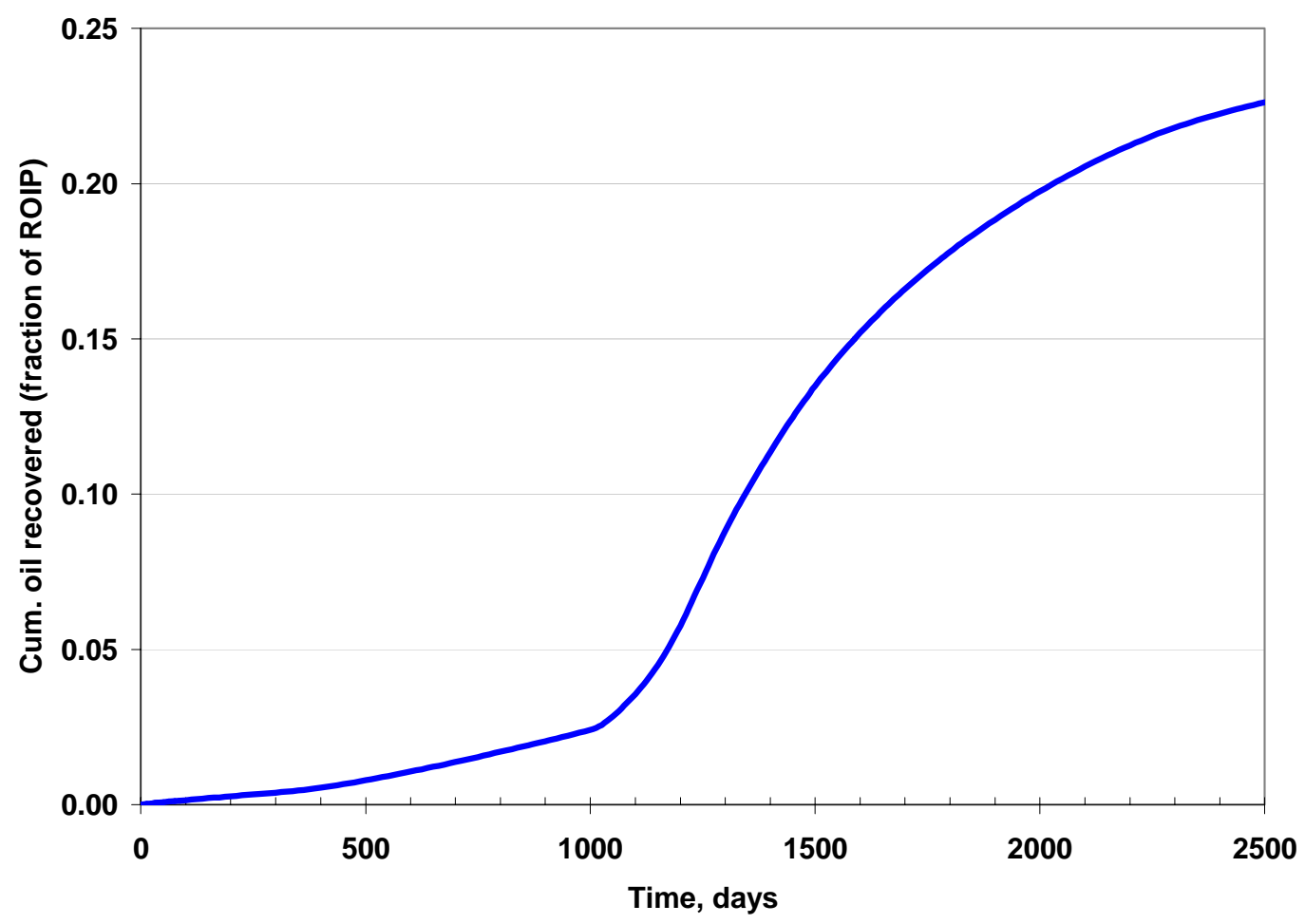

Fig. 3.11. Cumulative oil recovery for Case 2

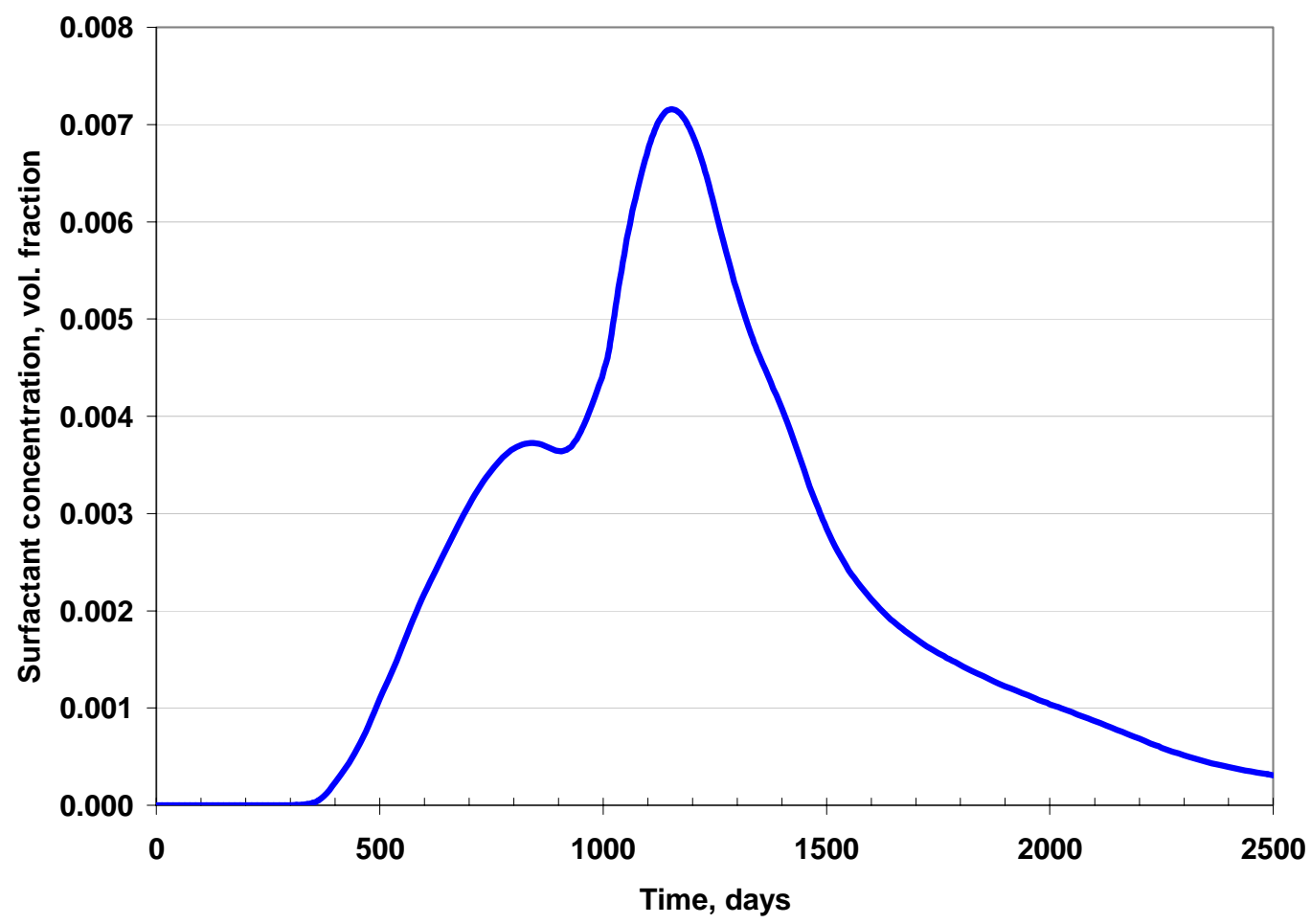

Fig. 3.12. Surfactant concentration history for Case 2 


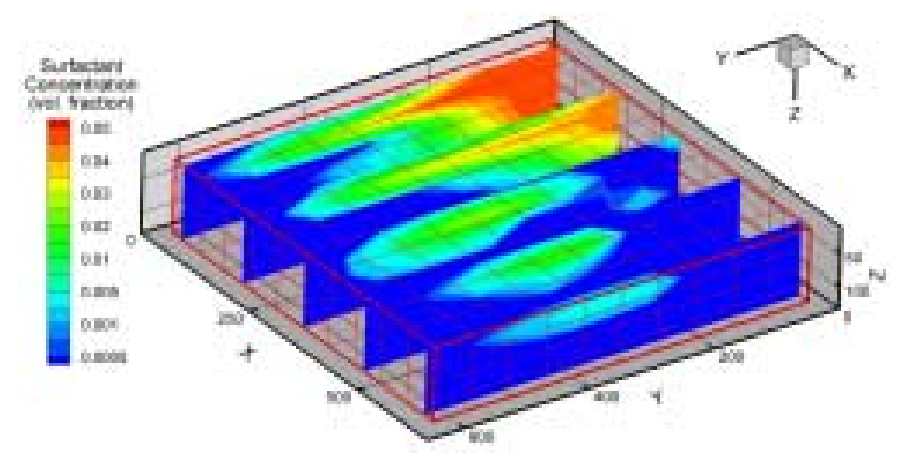

Fig. 3.13. Surfactant concentration profile at the end of chemical slug of $0.1 \mathrm{PV}$

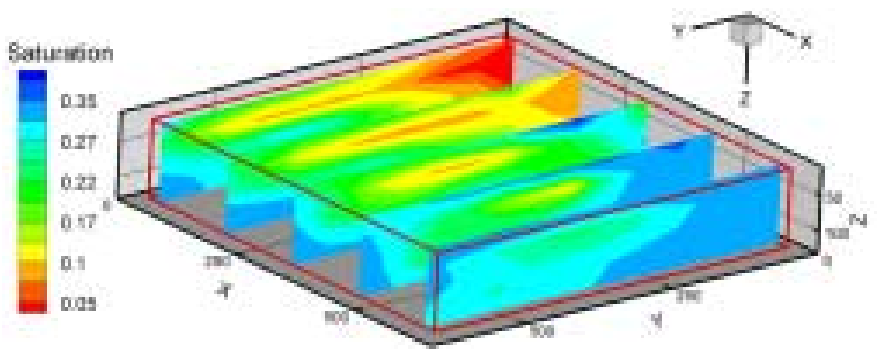

Fig. 3.14. Oil saturation distribution during post water flush at 0.5 PV

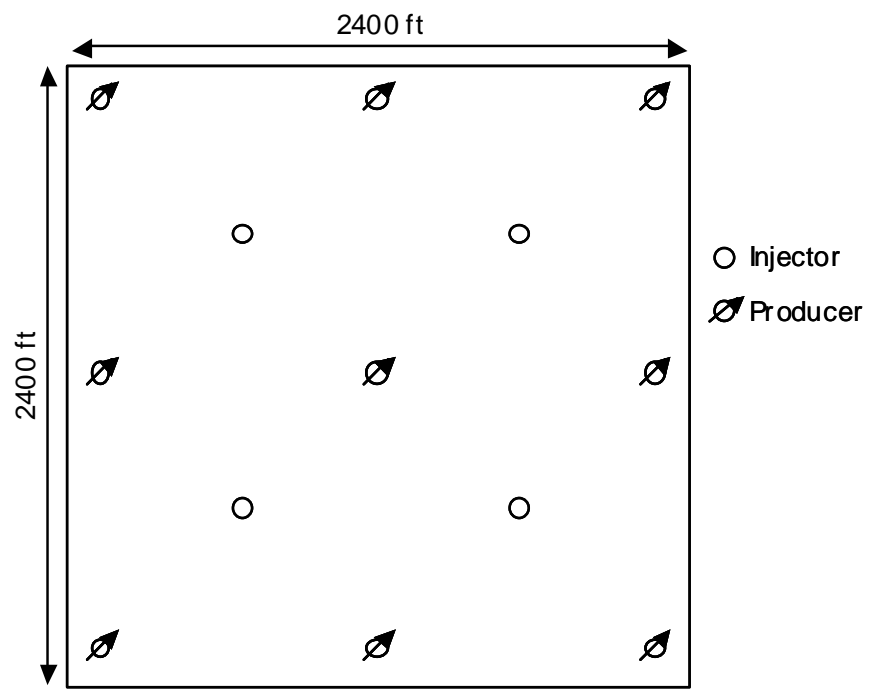

Fig. 3.15. Well locations for test Case 2 


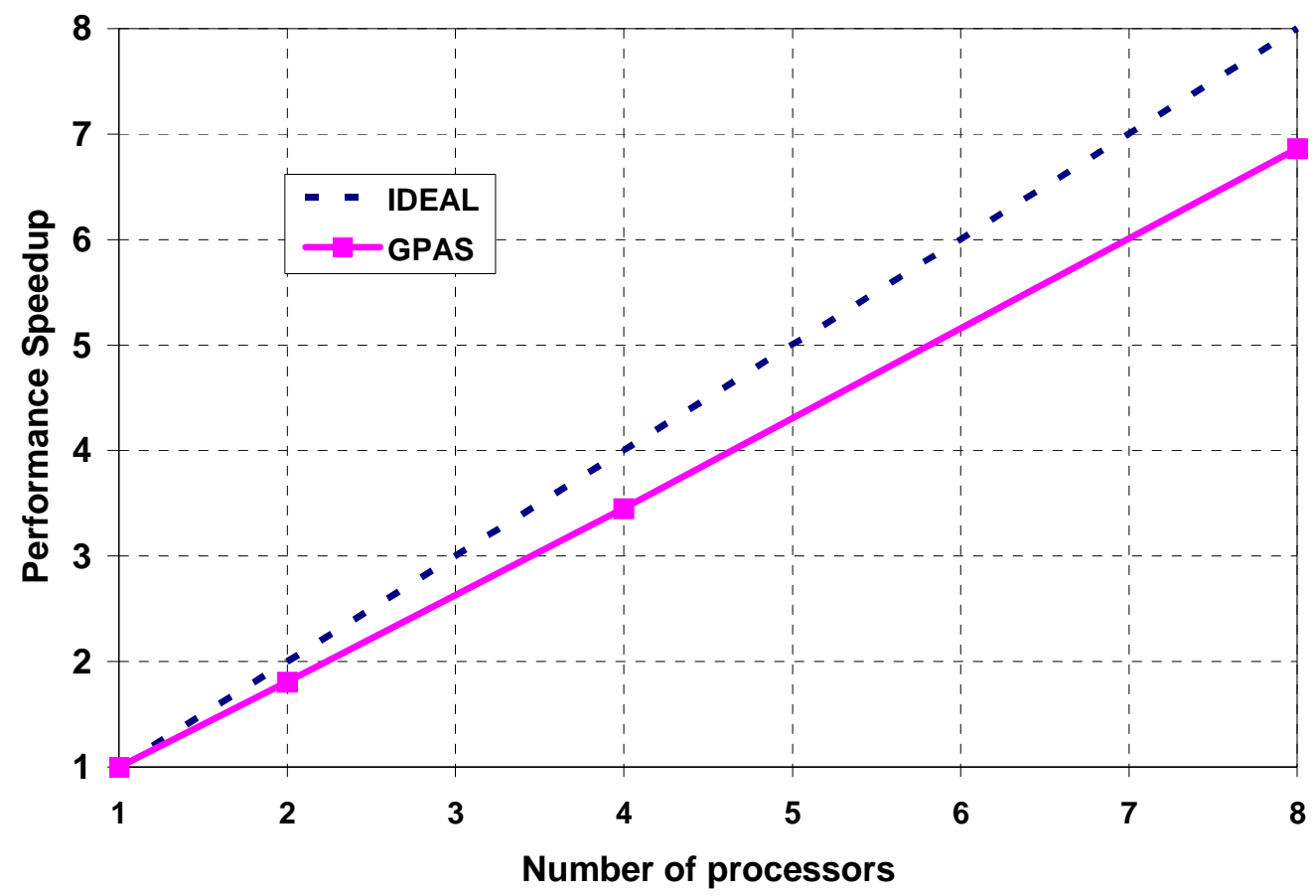

Fig. 3.16. Parallel speed up performance for surfactant/polymer flood (Case 2) 